\title{
A Review of fast-growing Blockchain Hubs in Asia
}

\author{
Yu Wang, Jing Ren, Caroline Lim, Swee-Won Lo \\ School of Business, Singapore University of Social Sciences, Singapore
}

Correspondence: carolinelimsl@suss.edu.sg

Received: 28 June 2019 Accepted: 26 July 2019 Published: 9 August 2019

\begin{abstract}
The unique combination of social and economic factors has brought about a dynamic and rapidly-evolving blockchain ecosystem in Asia. This paper systematically reviewed the development of four fast-growing blockchain hubs in Asia, namely China, Japan, Singapore and South Korea using secondary data sources. These countries are fast-growing based on the development of its digital, technological and regulatory infrastructure, patent applications, cryptocurrency trading volume and Initial Crypto-token Offerings (ICOs) activities. The review included insights into the different regulatory approaches, the blockchain startup scenes, selected enterprise or government-backed projects, as well as the research and educational landscape. Our findings suggested that the regulators, industry players, and academic institutions were purposeful and deliberate in nurturing blockchain technology innovation. Future development would be dependent on the regulatory, technological, as well as talent capability support unique to each blockchain hub.
\end{abstract}

Keywords: blockchain, cryptocurrency, regulation, fintech, ICO

JEL Classifications: D02, G18, H11, O20, O32, O50

\section{Introduction}

The blockchain technology, with its properties that distributes, disintermediates and decentralises, enables value to be unlocked for peer-to-peer exchange. This distributed ledger technology (DLT) can enforce "trust" such that a mutually distrusting community can collaborate and consent to a single version of the truth, which implies trade and exchange can occur between parties not known to each other.

These features of blockchain have enabled applications across different industries. Besides applications in trade, stocks and securities exchange, banking and finance, insurance, telecommunications, voting, health care, government administration, social networking and more, the blockchain technology holds promise to financial integration and inclusion [1]. The potential of blockchain is immense.

This paper is a systematic review of the development and application of blockchain in four Asian countries - China, Japan, Singapore and South Korea. These four countries have leveraged the entrepreneurial fervour and intensity of activities to shape themselves into blockchain hubs, evidenced by our analysis of their respective technological infrastructure, regulatory support, funding, and investment capital.

Literature in the inter-organisational relationship, including innovation and knowledge hubs, can be parsimoniously organised into two paradigms - network versus dyadic. Organisations in a network paradigm developed long-term and trusting relationships that were mutually reinforcing, and behaviours followed socially accepted norms. Organisations in a dyadic paradigm were opportunistic and sought to "maximise cooperation and minimise conflicts" [2].

As technology hubs serve the community in addition to organisational interests, we adopt the network paradigm in our definition of a hub. We define a hub as a locus of innovation and entrepreneurial activities that fuels the local economy as coordinating firms collaborate \& develop capabilities supported by different enablers. The literature described a financial technology ("FinTech" in short) hub to be characterised by sufficiently mature and developed technology infrastructure, availability of talented and receptive workforce (including investors, technologists, financiers), established regulatory support (e.g., favourable tax rates), involvement of the academia, government and enterprises 
in applied research and investment (e.g., accelerators, incubators, mentorship and seed funding), and a demand for FinTech (e.g., large volume of daily financial transactions, the need to enhance consumer experience and improve business efficiency, and the need for financial inclusion) [3].

A critical difference between FinTech and blockchain is that the latter can be applied beyond the financial industry. Blockchain allows parties with natural mistrust to collaborate and consent to a single version of the truth, thereby boosting business efficiency where cross-company and cross-industry collaborations are needed; it also holds promise to financial and social inclusion [1]. With these in mind, we propose the enablers of a blockchain hub to include the innovator group, infrastructure readiness and programme, availability of funding and capital, and the existence of demand for blockchain applications.

As one of the emerging new technology, blockchain drew investments in research and development of large technology firms and technology startups. We termed these technological firms and technology startups as innovator group. The innovator group represented technical capabilities to advance the development and application of blockchain. Funding and capital reflected the willingness and capabilities of individual and institutional investors to support technological development, especially for a relatively new and less-understood technology like blockchain. Infrastructure readiness and programme would facilitate the development of new and innovative technology. Apart from network and technology readiness, a friendly regulatory environment and availability of skilled talent pool would encourage and facilitate technological innovations. The economic and socioecological contexts could generate demand for blockchain applications; a politically stable economic environment could serve as a landing for blockchain projects addressing trust issues between and across partners. Similarly, the socio-ecological contexts could provide the impetus for financial and social inclusion.

This review intends to improve the understanding of blockchain development in different jurisdictions and contribute to current literature about blockchain in the Asia region. In the subsequent section, we explained the rationale of selecting the Asian countries, namely China, Japan, Singapore, and South Korea. In the third section, we analysed and compared the status of blockchain development in each country and inter-country. We concluded this paper with a discussion on the implications for future research and practice.

\section{Scope of Review}

In this section, we explained the selection criteria of the four countries in Asia, beginning with a description and analysis of four key enablers of a blockchain hub namely innovator group, infrastructure and programme, funding and capital, and demand.

\subsection{Innovator Group}

The actors in a network were central to the activities of a blockchain hub. These actors included large technology firms, blockchain startups and related technology unicorns who drew venture capital and drove spending in research and development (R\&D).

As of July 2018, China, Japan and South Korea were three Asian countries with the most number of Global 500 companies in the top ten of Fortune 500. Companies in Global 500 included large technology firms with research and investments in blockchain projects. In China, 46 of the 120 companies were involved in blockchain development representing sectors like banking, energy, IT, and motor. Japan's Sony and Fujitsu were also actively involved in blockchain projects. Almost all of the South Korea IT and motor companies in the Fortune 500, like Samsung, LG, and Hyundai, were exploring their own blockchain platforms.

Following the statistics of total blockchain-related patents filed globally by IPR Daily and Cintelliq, China filed the highest number of blockchain patents (41\%), followed by the United States $(32 \%)$. As of August 2018, Chinese companies occupied more than half of the top 100 companies globally for patents application on the blockchain (57 out of 100). Technology firms among them included Alibaba of China, Sony and Fujitsu of Japan and Coinplug of South Korea. The European Patent Office (EPO) showed a steady increase in patents granted normalised by population between 2009 to 2018 from countries like China, Japan, and South Korea. The year-on-year change of these three Asian countries over the period exceeded the figures reported for thirty-eight member states of EPO (including 28 states of the European Union).

Investment in blockchain startups represented the market expectation for blockchain development in the long-term. As of 31 March 2019, there were 333 technology unicorns worldwide between 2010 to 2019ii. Among them, more than one third (124) originated from Asia, of which China accounted for 89 unicorns. Another 15 unicorns originated from India, eight from South Korea, five from Indonesia, two from China SAR iii Hong Kong, one each in Japan and Singapore. Nine unicorns among them were blockchain-based in the areas of FinTech and cryptocurrency. These nine unicorns included six from China (e.g., Bitmain, Tiger Brokers), two from India (One97 Communications, PolicyBazaar), one from South Korea (Viva Republica). In China, where the regulation prohibited fund-raising through initial crypto-token 
offering (ICO), technology firms would become one of the main funding sources for blockchain startups.

National spending on research and development (R\&D) fueled the growth of the innovator group. According to data from the UNESCO Institute of Statistics published by the World Bank, high-income countries spent on average 2.36 per cent of GDP on R\&D for science and technology between 2000 to 2016 iv $^{\text {. Across }}$ countries in Asia, Japan's R\&D spending had consistently exceeded the average figure of high-income countries. The same index in South Korea rose steadily since 2000 to more than double that of high-income countries from 2012 onwards. Singapore's R\&D spending as per cent of GDP approximated close to high-income economies. China, on the other hand, did not perform close to other high-income countries on this index, but its $\mathrm{R} \& \mathrm{D}$ spending rose significantly from 0.89 per cent in 2000 to 2.11 in 2016. Other Asian countries performed below average relative to the rest of the world or when compared against high-income economies.

\subsection{Infrastructure and Programme}

The critical determinants of a blockchain hub included both digital and regulatory infrastructure of a country. We reviewed the digital infrastructure in two aspects, namely the network readiness and technology readiness. The World Economic Forum published the Global Information Technology Report ${ }^{\mathrm{v}}$ to assess the state of network readiness of 139 economies from the annual executive opinion survey. The index evaluated the quality of regulatory and business environment, information and communications technology (ICT) readiness in terms of affordability, skills and infrastructure, the role of the government, business sector and population as well as the environment, readiness and usage. Countries in Asia, including China, Malaysia, Mongolia, Sri Lanka, and Thailand, demonstrated steady improvements from 2012 to 2016. Across the drivers of network readiness in 2016, Singapore performed better than other advanced economies in business and innovation environment, skills, government usage, and social impacts. Taiwan performed the best in mobile network coverage and internet bandwidth infrastructure. Singapore was ranked first in 2015 and 2016; Japan was the other Asian country ranked in the top 10 of network readiness; the others in top 10 were made up mostly of European countries. Meanwhile, South Korea hovered around 10th to 13th position between 2013 to 2016 and was ranked 13 th in the most recent published ranking.

We further referenced the technological readiness ranking of eighty-two countries published by The Economist Intelligence Unit (EIU) as part of their medium- and long-term forecasts of the world's largest economies. The EIU assessed performance across three categories ${ }^{\text {vi }}$ access to the internet, digital economy infrastructure and openness to innovation. The index ranked each country for the historical period from 2013 to 2017 and forecasted change in performance for the period 2018 to 2022. Countries in Asia ranked in the top 10 included Singapore, Japan, South Korea, and Taiwan. Meanwhile, EIU forecasted improvements in technological readiness for these four countries/region and Hong Kong. In particular, the forecast projected Singapore to be ranked similarly to Australia and Sweden in technological readiness by the period 2018-2022.

Besides technological readiness, a workforce that was ICT-enabled, trained and skilled in blockchain development would more effectively contribute to the completion of innovative blockchain projects. According to the Global Startup Ecosystem Report [12], cities such as Beijing, Shanghai, Singapore, Bangalore, and Hong Kong possessed high-quality technology talents (such as top developers on GitHub and software engineers) that were relatively inexpensive compared to the US and European countries.

Workforce policies that encouraged science, technology, engineering and mathematics (STEM) training as well as lifelong learning in related skills and knowledge enhanced the adoption and development of blockchain technology. Preliminary results by the OECD reported that workforce capabilities and training received were associated with higher digital adoption, such as in cloud computing technology [4].

According to another OECD survey of adults aged between 16 and 65 in 35 economies in 2012 and 2015 Singapore (62\%) and South Korea $(60 \%)$ performed above the OECD average (55\%) for adult participation rates in structured training. In the same survey, Japan performed below the OECD average.

Apart from workforce policies, lower regulatory costs and simplified compliance procedures would expedite the process of starting a business, and these would be attractive factors for blockchain startups. As of 2018, the shortest time needed to start a business was in Hong Kong (1.5 days), Singapore (2.5 days), South Korea (4 days), Thailand (4.5 days), and Sri Lanka (9 days). In contrast, Cambodia took the longest time (99 days), followed by Laos (67 days), India (29.8 days), Philippines (28 days), China (22.9 days), and Vietnam (22 days).

On the other hand, the cost of business startup procedure (in per cent of gross national income per capita) including all official fees and legal costs was the lowest in Singapore $(0.5 \%)$, followed by China (0.6\%), Brunei, Hong Kong (1.1\%), and Mongolia (1.4\%) [5].

\subsection{Funding and Capital}


Funding and capital played an essential role in fueling the growth of blockchain startups and thus, the development of blockchain technology. Blockchain startups commonly raised funds through loans, donations, traditional venture capital, and ICOs [6].

Among them, ICO represented a unique fundraising method as it allowed blockchain startups to raise funds from the community at a relatively early stage. The value of ICO reflected the financial support that blockchain startups might receive and the size of the blockchain community within a region. In Asia, Hong Kong and Singapore were popular destinations for many blockchain entrepreneurs considering ICOs, after the prohibition of ICOs in mainland China and South Korea. As of October 2018, 8.14 per cent of ICOs globally occurred in Singapore and 2.81 per cent in Hong Kongrii. Vietnam and Japan led in the traffic to ICO listing websites globally, followed by the US and the United Kingdom. Other countries among the top 10 were China and South Korea [7]. Search volume from Google Trends suggested Asian countries and regions like China, South Korea, Singapore, and Hong Kong, to be among the top 10 worldwide for 'ICO'viii.

By the volume of venture capital and private equity activities, Hong Kong, Japan, and Singapore were among the most attractive countries/regions for venture capital and private equity globally. They were ranked 4th, 5th and 6th respectively, after the US, UK and Canadaix. Other Asian countries in the top 30 list included Malaysia, China, South Korea, Thailand, and India.

The trading volume of Bitcoin served as another indicator for the scale of capital in the country; an indicator of the cryptocurrency market that drew investors' attention. Asia accounted for almost a third of cryptocurrency transactions globally. According to LocalBitcoins.com, a decentralised bitcoin exchange website, the trading volume was US $\$ 6.3$ billion in July 2018, of which Asia contributed 32.8 per cent of the global volume of bitcoin traded [8]. Furthermore, statistics of the most-traded national currencies for bitcoin ${ }^{\mathrm{x}}$ showed a consistent trend - Japanese Yen accounted for around 40 per cent of the global total bitcoin volume, second to only US Dollar, with national currencies of other Asian countries such as South Korea, Indonesia, Thailand, Singapore, and Vietnam also among the top 20.

\subsection{Demand}

We proposed the demand for DLT as another enabler of a blockchain hub. Demand could stem from an economic infrastructure where multinational organisations converge as well as the socio-ecological landscape. DLT solved trust in digital asset transactions between businesses or between businesses and consumers without a central administrator [9].
The economic infrastructure of a country that would stimulate demand for blockchain applications included countries with active participation in the global production networks. We considered the global value chain participation since that reflected the relative positions of different economies in the global production networks. Forward or backward participation ratios measured each country's participation in the global value chain. Forward participation ratio measured participation through the supply side, i.e., the extent that "an economy's (or economic sector's) locally generated value-added was embedded in the production of other economies" [5]. Backward participation ratio measured participation through the demand side and "denotes the foreign value-added contribution to an economy's (or economy-sector's) exports" [5].

In Asia, Singapore led in the use of foreign inputs in the production of its exports, with a backward participation ratio of close of 60 per cent, followed by Vietnam, Taiwan (China), South Korea, and Malaysia. Brunei took the pole position in forward participation ratio at slightly more than 80 per cent, followed by Laos, Indonesia, Philippines, and Malaysia [5].

The need to resolve trust issues to boost efficiency and save cost through dis-intermediation using blockchain applications would emerge from countries with foreign direct investments (FDI). In 2017, the top three recipients of FDI in Asia was China, Hong Kong, and Singapore, followed by India, Indonesia, Japan, South Korea, Vietnam, and the Philippines [5].

A significant population of the working class in Asia earned their living outside of their home countries and remitted their earnings back to their home countries ${ }^{x i}$. In 2017, countries in the Asia Pacific region received US $\$ 266$ billion in remittances [5]. Globally the top three remittance recipient economies were in Asia, namely India, China, and the Philippines. There were two pain points to be addressed - trusted peer-to-peer funds transfer and remittance fees. Firstly, a large population in Asia were unbanked, although a majority of them owned mobile phones connected to a $3 \mathrm{G}$ or $4 \mathrm{G}$ network [10]. Secondly, the average cost of cross-border remittance fees for sending US $\$ 200$ remained high at seven per cent [11].

The socio-ecological context supported by a favourable regulatory environment and well-developed technological infrastructure laid the foundation for blockchain projects that would boost production efficiency or solve financial inclusion within the economy as well as the neighbouring region.

\subsection{Rationale}


Using national spending and patents filed as measures for the impact of the innovator group, countries like China, Japan, Singapore, and South Korea, performed better than other Asian countries. Moreover, China had the highest number of technology firms and technology unicorns. Technology firms provided alternative funding sources for blockchain startups.

While China's regulation prohibited cryptocurrency trading and ICOs, trading volume in bitcoin and other cryptocurrencies were high in Asian countries or regions like Hong Kong, Indonesia, Japan, Singapore, South Korea, Thailand, and Vietnam. Activities and interest in ICOs were also high. Drawing parallel from investment trends reported in Europe, investors would likely invest more in ICOs in investment destinations that appealed to VC and PE funds; destinations included China, India, Japan, Malaysia, Singapore, South Korea, and Thailand [12].

The readiness of technological infrastructure and programmes were critical to support innovation in blockchain technology. Singapore, Japan and South Korea led in technological readiness evident from our earlier analyses. Additionally, China, South Korea, Japan and Singapore were ranked in the top 10 by the 2018 Global Digital Economy Development Index that assessed the overall digital economy development in more than 150 countries and regions worldwide [13].

The enabling factors of a hub namely the availability of talent pool in the innovator group, funding and capital, infrastructure and programme as well as demands for business efficiencies or financial inclusion, allow blockchain projects to flourish. From the performance of these enablers, we identified China, Japan, Singapore and South Korea to be fast-growing blockchain hubs in Asia relative to other countries in the region.

\section{Analysis by Country}

We analysed the status of blockchain development in these four countries from four aspects: regulations and standards, characteristics of blockchain startups, enterprise- and governmentbacked blockchain projects, and research.

We extended our study of regulations to those for cryptocurrencies-related activities such as ICOs and cryptocurrency exchanges, to present a more comprehensive view of the state of blockchain in the country. Given alternative supporting resources through retail and institutional investors, enterprises, or the government, we conceded that the prohibition or absence of regulations for ICOs or cryptocurrency exchanges did not imply the lack of support for blockchain projects.

\subsection{China (Mainland)}

\subsubsection{Regulations and standards}

With the support of the Chinese government and available skilled workforce, the digital economy was a primary driver of economic growth in China contributing 30.3 per cent of China's GDP [14]. Before the state intervention on cryptocurrency trading, Chinese investors invested heavily in cryptocurrencies without knowledge of the market nor the underlying mechanism [15].

To mitigate financial risks brought about by the volatility of Bitcoin and cryptocurrencies, seven authorities in China issued a joint announcement in September 2017 to prohibit onshore and offshore platforms related to ICOs and cryptocurrency trading [16]. Nevertheless, the prohibition did not extend to the development of bitcoin's underlying technology - blockchain. Instead, the Chinese government took the lead in advocating the development of blockchain technology through a series of initiatives. In December 2016, the State Council of China included for the first time blockchain technology in the 13th Five-Year Plan to build a national strategic technological advantage. In June 2017, the central bank of China, People's Bank of China (PBoC), expressed their intent to promote research and application of advanced technologies such as blockchain and artificial intelligence (AI) in the five-year development plan for the financial industry [17]. Four months later, the Ministry of Industry and Information Technology (MIIT) released a white paper on China's Blockchain Technology and Application Development, the country's first official guidelines on the blockchain. Additionally, the State Council issued a mandate to the local government to accelerate the development of technologies, including blockchain in May 2018 [18]. Most recently in April 2019, the regulator, Cyberspace Administration of China, endorsed 197 blockchain service providers; the endorsement gave confidence to the industry for the deployment of their services.

To nurture this vibrant technology and innovation hub, the Chinese government further introduced regulatory guidelines for technology applications. A Fin'Tech committee was set up by $\mathrm{PBoC}$ to strengthen the application of Reg'Tech (regulation technology that addresses regulatory challenges in financial services using innovative technologies such as big data, AI, and blockchain) [19]. FinTech startups, namely Gingkoo and PeerSafe, have introduced regulatory frameworks and solutions on blockchain for domestic government and banks.

\subsubsection{Blockchain startups}

Despite the prohibition of ICOs, new blockchain companies in China outnumbered that of the US in 2016; these Chinese blockchain startups accounted for 28 per cent of new startups globally [20]. Furthermore, as at the end of 2017, China submitted 
the most patent applications for blockchain with 550 patent submissions, nearly twice that of 284 applications from the US [21].

There were over 400 blockchain startups in China as of March 2018, according to data from ITJuzi and BlockData. Instead of blockchain solutions, infrastructure and social media, the majority of Chinese blockchain companies focused on technology applications for the financial industry, and on traditional economic sectors like: agriculture, manufacturing, supply chain and logistics. Seventy-eight per cent of these operated out of Beijing, Shanghai, Shenzhen, and Hangzhou, which suggested an agglomeration effect.

Wanxiang Blockchain Labs, a non-profit research institution funded by China Wanxiang Holding setup the first blockchain research centre in Shanghai in 2015 to pioneer research, development, and application of the technology. Projects like Bubi Chain and Juzix worked on developing blockchain infrastructure to build the ecosystem. In the meantime, many startups have proposed blockchain-based commercial platforms to solve real-life issues. For example, Qulian Technology provided enterprise-level blockchain products and application solutions such as supply chain finance and traceability, digital certificate, and energy assets.

\subsubsection{Enterprise- and government-backed projects}

While startups experimented with new and novel ideas associated with blockchain, existing industry leaders explored potential solutions using blockchain technologies. The three Internet tech giants in China, Baidu, Alibaba and Tencent (collectively known as BAT), have started projects related to blockchain.

Baidu became a member of an open source industry blockchain initiative named Hyperledger in October 2017. Baidu has launched its blockchain-as-a-service (Baas) platform, and Alibaba has successfully applied blockchain in areas such as healthcare and ecommerce. Alibaba built a supply chain tracking system using blockchain technology together with PwC in March 2017. In the same year, Tencent invented the TrustSQL platform to develop blockchain applications and provide enterprise service solutions. Tencent established the first digital private bank in China, WeBank. Blockchain Open Source (BCOS) platform was the first commercial blockchain technology platform to be introduced in China jointly by Wanxiang Blockchain Labs and WeBank. Ant Financial, the financial affiliate of Alibaba, and Baidu published a white paper to illustrate their blockchain strategic roadmap in 2018. Besides BAT, other corporations like Huawei, Xunlei and JD.com (logistics tech giant) have incorporated blockchain into their firms' strategic plan and released white papers related to blockchain projects.
To support blockchain startups, the municipal governments of Chinese cities launched blockchain-dedicated funds. Example, Xiong'An Global Blockchain Innovation Fund equivalent to US\$1.6B was launched in Hangzhou in April 2018 $8^{\mathrm{xi}}$, and a district government of Nanjing city launched another blockchain fund of US\$1.4B in July 2018xii.

\subsubsection{Research}

Research in technology has been a focal area for the Chinese national and local government bodies. The volume of blockchain related publications and the number of research institutes increased rapidly in 2016. The number of blockchain research institutes that opened in the first four months of 2018 was equivalent to those that opened in the whole of 2017, which was three times the number in 2016 [22]. Apart from the government-led independent research institutes, corporations and universities established more than 90 per cent of the research institutes in China.

In 2017, the PBoC launched the Digital Currency Research Institute that focused on the development and research of digital currencies. So far, the Institute had filed more than 63 patent applications, according to China's State Intellectual Property Office (SIPO) [23, 24]. Its ultimate goal is to introduce a state-backed virtual currency that would combine blockchain-based cryptocurrencies with the existing monetary system.

\subsubsection{Hong Kong}

Hong Kong has been zoned a special administrative region compared to other cities in China mainland. Under the "one country, two systems" constitutional principle, Hong Kong maintained its own governmental system, legal, economic and financial affairs, including trade relations with foreign countries. This separate constitution enabled Hong Kong to play a vital role in promoting blockchain development in China and even the rest of Asia.

The Hong Kong government defined cryptocurrencies as "securities", similar to that of the US Securities and Exchange Commission (SEC). ICOs and cryptocurrency came under the Securities and Futures Commission (SFC). In November 2018, SFC defined a regulatory framework for trading, managing and distributing cryptocurrencies [25] which would facilitate the maturity of the regulatory framework in the long run for digital assets.

Meanwhile, the Hong Kong government supported the development of blockchain technology and related projects. As early as November 2016, the Hong Kong Monetary Authority (HKMA), jointly with Hong Kong Applied Science and 
Technology Research Institute (ASTRI), released a technical white paper on DLT. In the same month, HKMA-ASTRI FinTech Innovation Hub was launched to provide a neutral ground for the FinTech industry and startups in Hong Kong [26]. Later in March 2017, HKMA and seven banks commercialised a blockchain-based trade finance platform which was officially launched by HKMA on 31 October 2018, named "eTradeConnect". Developed by a consortium of twelve major banks in Hong Kong including HSBC and Standard Chartered Bank [27], e'TradeConnect aimed to improve trade efficiency, improve trust among trade participants, reduce risks and facilitate trade counterparties by leveraging digitalisation and blockchain technology.

HKMA collaborated with other regions and countries, including Singapore and Abu Dhabi. HKMA and Monetary Authority of Singapore (MAS) have signed and exchanged a Co-operation Agreement in 2017 to strengthen co-operation on FinTech [28] such as the Hong Kong Trade Finance Platform (HKTFP), an HKMA-led trade finance proof-of-concept based on DLT. In June 2018, HKMA worked with regulators in Abu Dhabi to develop a cross-border trade finance system using DLT [29]. These collaborative initiatives revealed the economic, technological and geographical advantages and capabilities of Hong Kong in the development of blockchain.

Besides government-run FinTech and blockchain projects, financial institutions, research centres and various startups have landed their projects in Hong Kong. Example, Ant Financial of Alibaba Group joined GCash of Philippines to launch the world's first blockchain-based remittance service built on Alipay blockchain technology [30]. The Bank of China Hong Kong developed a blockchain-based system for real estate appraisals to avoid mortgage fraud [31]. Over 20 various FinTech startups emerged from Hong Kong. Example, startup Crypto.com released Asia's first cryptocurrency Visa card in Singapore in September 2018 and subsequently in the US in November.

Blockchain research centres or laboratories by Deloitte and China Blockchain Application Research Centre were established in Hong Kong. Hong Kong University of Science and Technology received US\$20 million research grant for blockchain payment system. To attract blockchain talents, the Hong Kong government effected special immigration policy to expedite immigration for job seekers with blockchain expertise. It released a talent list on 28 August 2018 for eleven professions including blockchain technology [32]. The Hong Kong's Quality Migrant Admission Scheme (QMAS) that administered points-based tests for job seekers in Hong Kong accorded lower entry barrier to those with blockchain expertise.

\subsection{Japan}

\subsubsection{Regulations and standards}

Japan was the first country that recognised bitcoin as a legal payment option and has a national system to regulate cryptocurrency exchanges. A cryptocurrency exchange registered with the Financial Services Agency (FSA) of Japan was considered a legitimate entity in Japan. To-date, there were sixteen approved cryptocurrency exchange operators in Japan and cryptocurrencies on these exchanges could be exchanged for fiat monies or alternative cryptocurrencies. Basic guidelines for ICOs that focused on investor protection and anti-money laundering were released by a research group led by academics at Tama University $[33,34]$. Still under deliberation by the FSA, many anticipated that these guidelines would eventually pass as a law in Japan.

The regulatory landscape in Japan for cryptocurrency exchanges and ICOs paved a promising future for the development of blockchain projects. In 2016, the Ministry of Economy, Trade and Industry (METI) engaged Nomura Research Institute to survey domestic and international blockchain applications [35]. As an outcome of the survey, METI published the first version of evaluation templates to assess blockchain applications and completed the first evaluation for blockchain applications in healthcare, supply chain \& logistics, and smart property in 2018 $[36,37]$. The process uncovered legal and technical issues of blockchain applications for respective industries.

\subsubsection{Blockchain startups}

Compared to the exponential growth in bitcoin trading, the number of blockchain ventures in Japan was small relative to other regions in Asia. In 2016, among the 167 Fin'Tech startups in Japan, there were only 20 blockchain-related businesses [38]. This phenomenon in Japan could be attributed to the stronger public sentiment on the use of bitcoin for official payment than the application of the underlying blockchain technology.

Nevertheless, the blockchain startup scene in Japan was encouraging with generous support from the Japanese government. In 2017, METI sent three blockchain startups to the US as part of the Silicon Valley-Japan Bridge Project [39]. In the private sector, major industry players or financial institutions have announced investment funds, incubators or co-working space for blockchain startups. For example, SBI Holdings, a global rank-1 corporate blockchain investor, invested approximately US $\$ 460$ million in AI and blockchain fund [40]. Mizuho Financial Group, one of the three major financial institutions in Japan, sponsored Neutrino, the first blockchain co-working space in Japan [41]. In short, blockchain startups in Japan received assistance and mentorship from the government, enterprises and large financial institutions. Foreign startups in Japan had similar access to funding, facilities and advice on regulatory matters [42]. 


\subsubsection{Enterprise- and government-backed projects}

Enterprise-backed projects in Japan focused on building applications in financial services and supply chain. The Japan Exchange Group, Inc. (JPX) tested the streamlining of processes in the securities market and ownership registry through a proof of concept (POC) with six other financial institutions in Japan [43]. NT'T Data, one of the largest information technology companies, collaborated with Mitsubishi UFJ Financial Group (MUFG) and Singapore's National Trade Platform to launch a blockchain POC that would foster trade between Singapore and Japan [44]. With Skuchain, NTT DATA developed a business collaboration platform for Japanese manufacturers to boost supply chain efficiency [45].

The three financial institutions in Japan have implemented blockchain projects to streamline trading, payment, and other financial services. Mizuho Financial Group and Sumitomo Mitsui Financial Group (SMFG) respectively launched blockchain to streamline trade transactions $[46,47]$. On the other hand, MUFG introduced its MUFG Coin for commercial and retail customers, as well as to incentivise its employees to reduce overtime hours for healthier lifestyles [48].

At the government level, Japan's New Energy and Industrial Technology Development Organisation (NEDO) under the instructions of METI, worked on several blockchain-based projects. Among them included the use of internet-of-things (IoT) to streamline infrastructure for trade information sharing, where NEDO operated in partnership with NT'T Data. The Ministry of Internal Affairs and Communications explored the application of blockchain solution to process government tenders and introduced a roadmap for incorporating DLT in e-government services in 2018 [49].

The Blockchain Study Group, established by Deloitte Japan, Mizuho Financial Group, SMFG and MUFG, promoted blockchain adoption and education. The focus of this study group was to conduct studies on interbank payment and a Know-YourCustomer advanced platform. The Japan Blockchain Association facilitated collaboration and conversations between blockchain startups and the Japanese government. Other associations such as the Japanese Bankers Association whose members comprised banks, bank holding companies and bankers' association analysed the implementation of blockchain for financial services [50].

\subsubsection{Research}

Major financial institutions and universities led the blockchain research and development landscape in Japan. In April 2016, the Bank of Japan (BOJ) established the Fin'Tech Centre in its Payment and Settlement Systems Department [51]. The BOJ conducted a joint research project entitled "Stella" with the European Central Bank (ECB). The Stella project evaluated the performance of using Hyperledger Fabric to facilitate large value payments and the "delivery versus payment" environment using single and crossledger platforms, respectively [52,53]. In academia, Japan has five university nodes in the BSafe.network that promoted scientific and interdisciplinary social and economic research [54]. In addition, the more notable academic initiatives include the teaming of University of Tokyo and University of Aizu with two industry organisations to study smart currency [55], the establishment of BASE Alliance between Keio University and University of Tokyo [56], and the establishment of Blockchain Research Lab at Kyushu Institute of Technology [57].

\subsection{Singapore}

\subsubsection{Regulations and standards}

A confluence of factors - global financial centre, public-private partnerships, engagement and consultation, public education - had shaped Singapore's emergence as a leading technological hub of the world.

On the regulatory front, MAS, the central bank of Singapore, adopted a nurturing stance of regulation, one that was conciliatory but strict. In 2016, MAS introduced a "regulatory sandbox" to foster experimentation of innovative business models for financial institutions and Fin'Tech companies [58].

The MAS did not regulate Crypto-tokens, digital tokens or virtual currencies. Instead, the MAS regulated activities on the use of virtual currencies that would fall under the regulator's ambit, such as money laundering and terrorism financing. Digital tokens structured like securities in ICO, also known as equity tokens, must satisfy the requirements of the Securities and Futures Act (SFA). Cryptocurrency exchanges were regulated under the SFA by the MAS when such exchanges allowed the listing and trading of digital tokens.

Although the MAS had not issued specific legislation related to ICOs, it monitored activities and developments in the space carefully. Example, MAS issued a directive and warning to an ICO issuer to terminate its digital tokens offering in May 2018 as MAS assessed those digital tokens to represent equity ownership and they failed to satisfy SFA requirements [59].

To upskill the workforce in digital skills and promote lifelong continuous learning, Singapore's Ministry of Education launched a nationwide SkillsFuture Initiative. This Initiative provided subsidies on training and courses, including courses on blockchain. Singaporeans and permanent residents received up to seventy per 
cent in fee subsidy and to a maximum of 90 per cent subsidy for those aged above 40. Institutions of high learning and industry associations including local autonomous universities each undertook a digital skill including blockchain, to lead in capability development.

\subsubsection{Blockchain startups}

There were 270 Fin'Tech startups, including blockchain startups in Singapore [60]. Blockchain startups spanned across industries from the supply chain and logistics, social networking, FinTech, insurtech, gaming [61].

This year-to-date, Singapore was ranked third at 8.14 per cent relative to the world's total ICO projects after the US and UK $[62,63]$. The conducive regulatory environment, open and transparent business practices as well as the availability of skilled workforce, contributed to making Singapore an appealing hub for blockchain innovators and startups.

\subsubsection{Enterprise- and government-backed projects}

There were multiple prototypes, and POCs announced and implemented by consortia of conglomerates. In 2016, Bank of America Merrill Lynch, HSBC and the-then Infocomm Development Authority of Singapore built a POC to streamline the paper-based import/export documentation using the Hyperledger blockchain. PSA International, IBM Singapore and Pacific International Lines collaborated in August 2017 to develop a trial for blockchain-based supply chain business network solution. Singapore Airlines completed its POC in early 2018 for the world's first blockchain-based airline loyalty digital wallet that would allow frequent flyers to instantly convert air miles into loyalty tokens.

Besides investments by the private sector, "Project Ubin" by MAS jointly with the network of financial institutions, was launched to improve transparency and efficiency of clearing and settlement of payments and securities with DLT. To-date, "Project Ubin" had completed software prototypes of three different models of decentralised inter-bank payment and settlements.

\subsubsection{Research}

To stimulate research and development in the use of technology to improve quality of life and enhance economic opportunities, the government of Singapore set aside US $\$ 14$ million under the Research, Innovation and Enterprise 2020 plan [64].

In addition, IBM centre for blockchain innovation (ICBI) that was opened jointly with Singapore's Economic Development Board
(EDB), worked with government agencies, academia and other industry players to advance Singapore's contribution to FinTech innovation and facilitate the adoption of blockchain technology for finance, trade and commerce as well as develop the local workforce capabilities [65].

The National University of Singapore established an academic research laboratory and think tank for blockchain technology, CRYSTAL (cryptocurrency strategy, techniques and algorithms) Centre [66]. The Singapore University of Social Sciences FinTech \& Blockchain Group bridged academia and industry to build and develop capabilities and skills in Fin'Tech and blockchain through the twin engines of education and research that would realise financial integration and inclusion objectives.

As a blockchain hub, there were open dialogue and exchanges between regulatory, government and industry bodies in Singapore. Furthermore, voluntary and self-regulatory groups like Singapore FinTech Association, ACCESS (Association of Cryptographic Enterprises and Startups, Singapore) and BEST (Blockchain Enterprise and Scalable Technologies) Association, actively promoted the exchange of knowledge and best practices to advance the industry.

\subsection{South Korea}

\subsubsection{Regulations and Standards}

The government of South Korea supported the development and application of blockchain technology and have announced plans to invest over US\$900 million into blockchain initiatives by 2019. There were six pilot projects in the initiatives, including livestock history management, personal customs clearance, simple real estate transactions, online voting, international electronic document distribution, and maritime logistics [67]. To accelerate growth through innovation, the government announced plans to revise the existing tax regime that would motivate companies to focus on nascent technology development, like blockchain [68]. The strategy of the South Korean government was to construct an "Encrypted Valley" for the global blockchain industry in Industry 4.0.

The Korean Financial Services Commission (FSC) confirmed the prohibition of ICOs in January 2019. When the Korean Financial Investment Association established Korea's first blockchain alliance at the end of 2016, South Korean investors participated actively in cryptocurrency transactions and ICOs until September 2017. Subsequently, the FSC prohibited all ICOs and enforced their governance given the financial risks of cryptocurrency investments and transactions [69]. The Korean FSC started to restructure the regulation on cryptocurrency trading in 2018 as more cryptocurrency exchanges opened in the country; only twelve cryptocurrency exchanges have passed its security checks, while 
another eleven failed [70,71]. Following in August, the Blockchain Law Society issued a clear mandate to create a proper regulatory framework for the blockchain and associated cryptocurrencies.

\subsubsection{Blockchain startups}

South Korean blockchain startups covered a range of industries, such as FinTech, insurance, social media, entertainment, real estate. Some of the most promising blockchain startups in South Korea worked on blockchain infrastructure \& services (e.g. Icon, Blocko, Deblock), Fin'Tech (e.g. Proof Suite, theLoop), cryptocurrency exchanges (e.g. Upbit, Korbit, Coinone), and social media services (e.g. Foresting, Lucidity). The startup Coinplug, supplied multiple blockchain related services like digital asset exchange, an identitybased blockchain platform and online service platform. Coinplug held the most patents in blockchain in South Korea and was ranked seventh globally in 2018 .

The startups in South Korea sourced funding from the local and global technology giants. For example, Blocko that provided a platform for blockchain solutions had secured US\$8.9 million in Series B funding from Samsung SDS early in 2016. Cultural exports were integral to South Korean GDP. Muzika, a blockchain startup, had attracted over ten thousand musicians and 2 million users from 150 countries globally, as well as crypto and blockchain investment groups [72].

\subsubsection{Enterprise- and government-backed projects}

To develop skilled talent in blockchain, the Minister of Science and ICT in South Korea announced new initiatives valued at US\$720,000 in addition to the original $\$ \$ 900$ million, to train students, construct blockchain research centres and foster 10,000 professionals by 2022 [73]. In September 2018, the government established an open-source blockchain platform, dubbed Gold Ore. This platform signed an agreement with multiple international organisations, such as the Korean Standards Association, Japan Blockchain Consortium and others, to conduct blockchain-related training for the industry.

On the enterprise side, Samsung launched its blockchain platform hosted in the cloud, named "Nexledger", in 2017. Nexledger applications covered digital identity, digital payment, digital stamping, supply chain finance, global warranty and digital provenance [74]. Besides Samsung, the LG launched its blockchain service platform in May 2018, named "Monachain". This platform offered digital authentication, community token and supply chain management for the finance, public, telecommunications and manufacturing industries [75]. Hyundai Group had made a substantial investment on the internet of things (IoT) side of blockchain.
The South Korean internet company, Kakao launched its blockchain subsidiary, GroundX, in March 2018. To-date, Ground $\mathrm{X}$ had over 50 million monthly developers to create blockchain services on its global public blockchain. In May 2018, ICON and LINE co-founded Unchain to build LINE's blockchain network. Unchain would develop various DApp services and expand the blockchain ecosystem.

\subsubsection{Research}

In December 2016, a group of twenty-one financial investment companies and five blockchain technology firms signed a Memorandum of Understanding to form a distributed ledger solution as a blockchain consortium. This consortium marked the first attempt in South Korea where multiple financial firms leverage blockchain technology for development.

At present, most blockchain developers worked from universities in South Korea, including Seoul National University, Korea University, Sogang University, Yonsei University. These universities launched blockchain related courses. Decipher, a think-tank in blockchain research at the Seoul National University made up of master- and doctoral-level researchers had engaged in blockchain research for over three years. There had been various collaborations between university and industry to nurture skilled blockchain professionals, such as the collaboration between Korea University and Huobi.

\subsection{Comparison across Countries}

Table 1 summarises the status of blockchain development in each of the four countries.

\section{Conclusion and Discussion}

\subsection{Conclusion}

From the previous and current state analysis of infrastructure and programme, Asian countries like Japan, Singapore, and South Korea stood out in technological readiness, as well as digital and regulatory infrastructure. Although China had yet to make its way into front ranking in global surveys, the country performed the best in terms of patents granted normalised by population. Enterprisebacked blockchain projects contributed to the volume of patent applications led by Chinese technology firms such as the BAT, Huawei, Xunlei, and JD.com. Chinese provincial governments encouraged technology development using blockchain-dedicated funds.

The focus areas for blockchain-based solutions differed across countries. Solutions by enterprise-backed projects in Singapore 
Table 1. Blockchain development status summary

\begin{tabular}{|c|c|c|c|c|}
\hline $\begin{array}{c}\text { Four } \\
\text { Enablers }\end{array}$ & China & Japan & Singapore & South Korea \\
\hline $\begin{array}{l}\text { (I) } \\
\text { Regulation } \\
\text { and } \\
\text { standards }\end{array}$ & $\begin{array}{l}\text { - ICO \& cryptocurrency } \\
\text { trading banned except in } \\
\text { Hong Kong where } \\
\text { cryptocurrencies treated as } \\
\text { securities } \\
\text { - Blockchain advocated by the } \\
\text { government } \\
\text { - Fintech committee by the } \\
\text { central bank (BoC) and } \\
\text { blockchain included } \\
\text { - First batch of blockchain } \\
\text { service providers officially } \\
\text { registered }\end{array}$ & $\begin{array}{l}\text { - First country to recognise } \\
\text { bitcoin as a legal payment } \\
\text { option } \\
\text { - Legalised cryptocurrency } \\
\text { exchanges } \\
\text { - Working towards legalising } \\
\text { ICOs } \\
\text { - Devising evaluation } \\
\text { framework for blockchain } \\
\text { projects }\end{array}$ & $\begin{array}{l}\text { - Cryptocurrency regulated if } \\
\text { structured like a security } \\
\text { - Cryptocurrency exchanges } \\
\text { that offered listing and } \\
\text { trading of digital tokens } \\
\text { regulated under the SFA by } \\
\text { the MAS } \\
\text { - Cryptocurrency monitored } \\
\text { for money laundering \& } \\
\text { terrorism financing activities } \\
\text { - Fintech regulatory } \\
\text { sandboxes launched }\end{array}$ & $\begin{array}{l}\text { - ICO banned outright } \\
\text { - Cryptocurrency exchanges } \\
\text { legalised } \\
\text { - Blockchain advocated as } \\
\text { existing tax regime being } \\
\text { revised to encourage } \\
\text { blockchain companies) }\end{array}$ \\
\hline $\begin{array}{l}\text { (II) } \\
\text { Blockchain } \\
\text { startups }\end{array}$ & $\begin{array}{l}\text { - Accounting for } 28 \% \text { of new } \\
\text { blockchain startups globally in } \\
2017 \\
-78 \% \text { are in } 4 \text { major cities } \\
\text { - Areas: technology } \\
\text { applications \& enterprise-level } \\
\text { blockchain solutions (e.g., } \\
\text { Bubi Chain, Juzix \& Qulian) }\end{array}$ & $\begin{array}{l}\text { - } 20 \text { out of } 167 \text { fintech } \\
\text { startups are blockchain- } \\
\text { related in } 2016 \\
\text { - Supported by enterprises \& } \\
\text { governments (e.g. NTT } \\
\text { Data, Skuchain, METI) } \\
\text { - Areas: IoT, gaming \& } \\
\text { energy industry }\end{array}$ & $\begin{array}{l}\text { - } 270 \text { FinTech start-ups } \\
\text { including blockchain start- } \\
\text { ups } \\
\text { - Areas: applications in } \\
\text { supply chain \& logistics, } \\
\text { social networking, fintech, } \\
\text { insurtech, gaming, financial } \\
\text { exchanges, cloud } \\
\text { infrastructure, payment \& } \\
\text { remittances (e.g., Qtum, } \\
\text { NEO \& VeChain) }\end{array}$ & $\begin{array}{l}\text { - Supported by big } \\
\text { enterprises (e.g. Samsung } \\
\text { sponsored Blocko early) } \\
\text { - Coinplug ranked in 7th in } \\
\text { blockchain patent filed } \\
\text { - Areas: fintech, insurance, } \\
\text { social media, entertainment } \\
\text { \& real estate }\end{array}$ \\
\hline $\begin{array}{l}\text { (III) } \\
\text { Enterprise- } \\
\text { and } \\
\text { government- } \\
\text { backed } \\
\text { projects }\end{array}$ & $\begin{array}{l}\text { - Big companies like BAT, } \\
\text { Huawei, Xunlei \& JD.com } \\
\text { have started projects related to } \\
\text { the blockchain (e.g. Tencent } \\
\text { created the 1st digital private } \\
\text { bank WeBank \& the } \\
\text { TrustSQL blockchain } \\
\text { platform; Alibaba built a } \\
\text { supply chain tracking system } \\
\text { using blockchain together with } \\
\text { PwC) } \\
\text { - Government-backed } \\
\text { blockchain funds launched in } \\
\text { a few cities (e.g. \$1.6B } \\
\text { launched in Hangzhou \& } \\
\$ 1.4 B \text { in Nanjing) } \\
\text { - HKMA \& } 12 \text { banks released } \\
\text { a blockchain-based trade } \\
\text { finance platform } \\
\text { eTradeConnect }\end{array}$ & $\begin{array}{l}\text { - NEDO on IoT for trade } \\
\text { information sharing } \\
\text { - MIAC on government } \\
\text { tenders \& e-government } \\
\text { services } \\
\text { - Deloitte Japan, Mizuho, } \\
\text { SMFG \& MUFG on } \\
\text { interbank payment and KYC } \\
\text { platform } \\
\text { - JPX \& } 6 \text { financial } \\
\text { institutions on streamlining } \\
\text { financial services } \\
\text { - NTT Data on supply chain } \\
\text { efficiency }\end{array}$ & $\begin{array}{l}\text { - MAS Project Ubin for } \\
\text { settlement of payments \& } \\
\text { securities between financial } \\
\text { institutions and the central } \\
\text { bank led the project } \\
\text { - A project between Bank of } \\
\text { America Merrill Lynch, } \\
\text { HSBC \& IMDA on trade } \\
\text { documentation using } \\
\text { blockchain technology } \\
\text { - Singapore Airline's } \\
\text { blockchain-based airline } \\
\text { loyalty digital wallet } \\
\text { - Singapore Smart Nation } \\
\text { Initiative to improve living } \\
\text { with new and emerging } \\
\text { technology }\end{array}$ & $\begin{array}{l}\text { - Government-backed } \\
\text { blockchain talent project } \\
\text { (e.g. MOS \& ICT planning } \\
\text { to invest US } \$ 720 \mathrm{k} \text { to } \\
\text { construct blockchain } \\
\text { research centres and foster } \\
10,000 \text { professionals by } 2022 \\
\text { - The government } \\
\text { established an open-source } \\
\text { blockchain platform named } \\
\text { Gold Ore } \\
\text { - Tech giants are investing in } \\
\text { blockchain development } \\
\text { (e.g. Samsung, LG \& Kakao } \\
\text { launched blockchain } \\
\text { platform Nexledger; LG } \\
\text { launched blockchain service } \\
\text { platforms) }\end{array}$ \\
\hline $\begin{array}{l}\text { (IV) } \\
\text { Research }\end{array}$ & $\begin{array}{l}\text { - Surge in the number of new } \\
\text { blockchain research institutes } \\
\text { observed from } 2016 \text { to } 2018 \\
\text { - More than } 90 \% \text { of research } \\
\text { institutes were established by } \\
\text { corporations and universities } \\
\text { - PBoC launched the Digital } \\
\text { Currency Research Institute } \\
\text { that focuses on the } \\
\text { development \& research of } \\
\text { digital currencies }\end{array}$ & $\begin{array}{l}\text { - Led by major financial } \\
\text { institutions \& universities } \\
\text { - Bank of Japan's FinTech } \\
\text { Centre for payment \& } \\
\text { settlement } \\
\text { - BSafe.network led by the } \\
\text { University of Tokyo forming } \\
\text { a blockchain research } \\
\text { network for with over } 30 \\
\text { member universities } \\
\text { worldwide } \\
\text { - University \& industry } \\
\text { collaborations for applied } \\
\text { research on smart currency } \\
\text { \& blockchain } \\
\end{array}$ & $\begin{array}{l}\text { - Supporting research \& } \\
\text { development in the national } \\
\text { RIE } 2020 \text { plan } \\
\text { - University, government \& } \\
\text { industry collaboration (e.g. } \\
\text { the IBM centre for } \\
\text { blockchain innovation, the } \\
\text { Cryptocurrency Strategy, } \\
\text { Techniques \& Algorithm } \\
\text { Centre at NUS, FinTech \& } \\
\text { Blockchain Group at SUSS) } \\
\text { - Volunteer groups of self- } \\
\text { regulatory organisations (e.g. } \\
\text { SFA, ACCESS \& BEST) }\end{array}$ & $\begin{array}{l}\text { - Financial and tech firms } \\
\text { assigned MOU for } \\
\text { blockchain consortium } \\
\text { development. } \\
\text { - Blockchain training } \\
\text { courses launched in many } \\
\text { universities } \\
\text { - Universities \& industry } \\
\text { collaborating on blockchain } \\
\text { research \& application (e.g. } \\
\text { Korea University } \\
\text { collaborating with Huobi } \\
\text { and KEB) }\end{array}$ \\
\hline
\end{tabular}

were related to trading and finance like those on the streamlining of import/export documentation, supply chain solutions and interbank payment and settlements. In Japan, enterprise-backed projects were related to information sharing by financial institutions and government agencies. Like China, technology firms in South Korea, such as Samsung, LG, and Hyundai, initiated various enterprise-backed projects on blockchain technology. 
These developmental activities created a value chain of activities and opportunities.

Blockchain startups in China and South Korea built applications across a wide spectrum from FinTech, insurance, social media, to real estate, and more. On the other hand, the startups in Japan and Singapore tended towards FinTech applications. English is the official business language in Singapore; this appealed to investors and blockchain entrepreneurs globally. Perceived as a gateway in the east to countries in the west, startups from China, such as Qtum, NEO, and VeChain, had registered their firms in Singapore. The source of funding and capital for startups at their early stage in China, Japan, and South Korea, were mostly domestic.

The existing regulations in China and South Korea prohibited the exchange and trading of cryptocurrencies and ICO. Meanwhile, Japan and Singapore adopted a more nuanced stance and issued clear policy statements. The former legislation protected investors' interest and the latter statutory and regulatory approach could motivate blockchain startups in fulfilling their project objectives. All four countries nurtured investments and developments in blockchain technology. For example, blockchain was included in official documents released by the Chinese national government and the first batch of blockchain projects were endorsed with service provider licenses. Likewise, the Japanese government published an evaluation framework for blockchain-based projects. South Korea revised its tax regime to encourage blockchain companies. The central bank of Singapore launched Fin'Tech regulatory sandboxes in 2016 to promote and nurture technology innovation.

Although there were many blockchain startups or projects backed by large enterprises and government, to-date no blockchain-giants had emerged. We anticipated Japan to lead on the regulatory infrastructure front being one of the first to accept cryptocurrencies by legalising cryptocurrency exchanges, and the publication of a government-led evaluation framework for blockchain projects. The abundant technical talent pool in China among the innovator group might accelerate the growth of the hub. In Singapore, the favourable environment for ICO financing could support the funding requirements of blockchain startups with strong offerings. Although a small city-state relative to China, Japan and South Korea, the domestic talent gap, particularly in technical know-how could be mediated by Singapore's language capability and proximity to countries in Southeast Asia.

\subsection{Discussion}

This essay contributed to the growing body of literature on blockchain and informed the state of blockchain development in Asia. We reviewed the stage of development in four different countries in Asia and found these countries to have possessed similar characteristics in their blockchain ecosystem: innovators and developers supported by regulatory and digital infrastructure, funding and capital, as well as programmes for workforce capability development against ready demand for distributed ledger or blockchain technology.

The performance of these four enablers would impact the speed of development of each hub given the nascent state of blockchain development.

On the regulation front of the infrastructure and programme enabler, we projected the pace of change to differ by countries.

The regulators of these four countries we have reviewed shared similar approach towards the blockchain technology - a deliberate and agile strategy to protect the public's interest while advocating technology innovation. Industry bodies could be the catalyst to initiate self-regulating organisations to network, exchange knowledge and best practices, promote standards, and engage the startups and regulators constructively.

As each of the four countries competes to attract and develop technical expertise in blockchain technology, they would have to harness their unique value propositions to develop capabilities and sustain the hub of activities.

\subsection{Future Trends}

Going forward, two factors shape the developments of these blockchain hubs - one factor at the network level facilitated by one or more catalyst firms and another within the network.

In the network paradigm of a hub, Dhanaraj and Parkhe identified the role of a catalyst firm in a hub that comprised of diverse stakeholder groups [2]. We drew parallel in forecasting the future developments of blockchain hubs. The presence of a catalyst firm in a blockchain hub would accelerate development to realise both economic and social impact of the hub. Such a catalyst firm could be the coordinator between regulators and startups to facilitate communication and knowledge sharing. Any organisation could step up to be the catalyst, such as an industry association, a research institute, a government agency or even a technology corporation.

The second influencing factor for the future of these blockchain hubs would be endogenous in the network. By this, we refer to the capabilities of the workforce in a blockchain hub. These capabilities of a blockchain hub shape the speed of its future development. Capabilities include technical skills and capabilities, as well as the language communication skills of the workforce to transcend cultural differences and collaborate with global teams. 


\subsection{Limitations}

\subsubsection{Biases from language}

The data collected for analyses of this paper were predominantly in English. For example, a patent application might be filed in vernacular languages instead of English in countries like China, Japan, and South Korea. Google Trends was the primary source to gather search trends for ICOs. This approach introduced biases in our study of China, Japan, and South Korea, where official languages were non-English. We attempted to minimise such biases by collecting data from multiple sources. Future research could introduce expert opinion surveys in respective local languages for comparative analyses.

\subsubsection{Temporal analysis and quantitative analysis}

Although we had systematically investigated each of the four hubs separately, focusing on its regulation, standards and research development over time, this paper had not addressed agglomeration effects within the country. First-tier cities in China such as Beijing, Guangzhou, and Shanghai were key contributors to patents filed and granted. Subsequent research could extend beyond country-level analyses to study the agglomeration effects within the country.

This paper served as a qualitative analysis across blockchain hubs in Asia. Subsequent research using quantitive analysis could consider quantifying each of the enablers as inputs into an index to monitor and track the development of blockchain hubs through inter-temporal analysis, regionally and globally.

\section{Competing Interests:}

None declared.

\section{Ethical approval:}

Not applicable.

\section{Author's contribution:}

$Y W, J R, C L$ and SWL designed and coordinated this research and prepared the manuscript in entirety.

\section{Funding:}

None declared.

\section{Acknowledgements:}

YW, JR, CL and SWL deeply thank Professor David Lee for his guidance and Ms Sherry Li for ber support.

\section{References:}

[1] D. K. C. Lee, and L. Low, "Inclusive Fintech: Blockchain, Cryptocurrency And ICO”, World Scientific, Singapore, 2018.

[2] C. Dhanaraj, and A. Parkhe, "Orchestrating Innovation Networks", The Academy of Management Review, vol. 31, no. 3, pp. 659-669, Jul. 2006.

[3] S. Chishti, and J. Barberis, The FinTech Book. Chichester : John Wiley \& Sons, 2016.

[4] D. Andrews, G. Nicoletti and C. Timiliotis, "Digital technology diffusion: A matter of capabilities, incentives or both?", OECD Economics Department Working Papers, No. 1476, OECD Publishing, Paris, Jul. 2018. [Online]. Available: doi.org/10.1787/7c542c16-en. [5] Asian Development Bank, Key Indicators for Asia and the Pacific 2018 (49th Edition). Manila: Asian Development Bank, 2018.

[6] D. K. C. Lee, M. Chwierut, W. Anderson, B. Lio, and B. Downes, "The Characteristics of Token Investors", in book "Inclusive Fintech: Blockchain, Cryptocurrency And ICO”, World Scientific, Singapore, pp. 125-172, 2018.

[7] A. Kerya, "ICO Statistics: Countries, Traffic, and Investors", Medium.com, Jun. 2018. Accessed on: Oct. 6, 2018. [Online]. Available at URL: https://medium.com/@incryptico.com/ico-statistics-countriestraffic-and-investors-4e830e0438b0.

[8] T. Alford, "Bitcoin Adoption: Trading Volume by Country", TotalCrypto.io, Aug. 2018. Accessed on: Oct. 6, 2018. [Online]. Available at URL: https://totalcrypto.io/bitcoin-adoption-trading-volumecountry/.

[9] A. Wright, and P. De Filippi, "Decentralized Blockchain Technology and the Rise of Lex Cryptographia”, 2015. Available at SSRN 2580664.

[10] A. Demirgüç -Kunt., L. Klapper, D. Singer, S. Ansar, and J. Hess, The Global Findex Database 2017: Measuring financial inclusion and the fintech revolution. The World Bank, 2017.

[11] The World Bank. "Record High Remittances Sent Globally in 2018". Retrieved from World Bank Group - International Development, Poverty \& Sustainability. Apr. 2018. [Online]. Available at URL: https://www.worldbank.org/en/news/pressrelease/2019/04/08/record-high-remittances-sent-globally-in-2018. [12] Startup Genome, "Global Startup Ecosystem Report 2019", San Francisco: Startup Genome LLC, 2019.

[13] Aliresearch and KPMG, "Welcoming a New Wave of Global Economy: Digital Economy Development Global Index 2018”, Sep. 2018. Accessed on: Sep. 28, 2018. [Online]. Available at URL: http://www.199it.com/archives/774852.html.

[14] China Academy of Information and Communications Technology (CAICT), "White Paper on the Development of the Digital Economy in China”, CAICT, Jul. 2017. Accessed on: Aug. 25, 2018. [Online]. Available:

http://www.cac.gov.cn/files/pdf/baipishu/shuzijingjifazhan.pdf. [15] L. Liu, and Q. Wang, "Analysis of Bitcoin Herd Behavior Based on Imitation and Infection Model", Journal of Beijing University of Posts and Telecommunications (Social Sciences Edition), Vol.17, No.2, pp.2733, 2015.

[16] Ministry of Industry and Information Technology (MIIT),

"Announcement on preventing financial risks of ICOs", 2017. Accessed on: Sep. 26, 2018. [Online]. Available at URL:

http://www.miit.gov.cn/n1146290/n4388791/c5781140/content.html. 
[17] National Development and Reform Commission (NDRC), "The 13th five-year plan for economic and social development of the People's Republic of China (2016-2020)", Central Compilation \& Translation Press, 2017. Accessed on: Sep. 20, 2018. [Online]. Available: http://en.ndrc.gov.cn/newsrelease/201612/P020161207645765233498. pdf.

[18] M. Amsili, "Blockchain in China: Local is Everything", supchina, Aug. 2018. Accessed on: Sep. 20, 2018. [Online]. Available at URL: https://supchina.com/2018/08/28/blockchain-in-china-local-iseverything/.

[19] G. Sun, "Expectations on the Development of Blockchain in China”, Caixin, Jun. 2017. Accessed on: Sep. 27, 2018. [Online]. Available at URL: http:/ /opinion.caixin.com/2017-06-

17/101102805.html.

[20] Wuzhen Think Tank, "The white paper on the development of China's blockchain industry”, 2017. Accessed on: Sep. 23, 2018. [Online]. Available: http://sike.news.cn/hot/pdf/12.pdf.

[21] C. Liu, "Blockchain - A Guide for Officials," People's Daily Press, pp.132-134, 2018.

[22] X. Fei, and S. W. Li, "Blockchain Courses Among Global Universities and Blockchain Research Institutes in China", BlockData, 2018. Accessed on: Sep. 29, 2018. [Online]. Available at URL: https://www.8btc.com/article/195209.

[23] M. Xing, "63 patent applications filed by the PBoC digital currency research institute”, Jun. 2018. Accessed on: Oct. 2, 2018. [Online]. Available at URL:

http://finance.ce.cn/rolling/201806/29/t20180629_29567884.shtml. [24] W. Zhao, "South Korea Plans Tax Perks for Blockchain Startups", coindesk, Jul. 2018. Accessed on: Sep. 28, 2018. [Online]. Available at URL: https://www.coindesk.com/south-korea-plans-tax-perks-forblockchain-startups/.

[25] Securities and Futures Commission (SFC), "SFC warns of cryptocurrency risks", Feb. 2018. Accessed on: Sep. 1, 2018. [Online]. Available at URL:

https://www.sfc.hk/edistributionWeb/gateway/EN/news-andannouncements/news/doc?refNo=18PR13.

[26] Applied Science and Technology Research Institute (ASTRI), "HKMA-ASTRI Fintech Innovation Hub", Nov. 2016. Accessed on: Sep. 12, 2018. [Online]. Available at URL:

https://www.astri.org/technologies/joint-research-laboratories/rdcentres/hkma-astri-fintech-innovation-hub/.

[27] HKMA, "Fintech Co-operation between the Hong Kong Monetary Authority and the Financial Services Regulatory Authority of Abu Dhabi Global Market”, Jun. 2018. Accessed on: Sep. 10, 2018. [Online].

Available at URL: https://www.hkma.gov.hk/eng/key-

information/press-releases/2018/20180626-4.shtml.

[28] HKMA, "Fintech Collaboration between the Hong Kong Monetary Authority and the Monetary Authority of Singapore", Oct. 2017.

Accessed on: Sep. 10, 2018. [Online]. Available at URL:

https://www.hkma.gov.hk/eng/key-information/press-

releases/2017/20171025-4.shtml.

[29] HKMA, "The launch of eTradeConnect and the Collaboration with we.trade”, Oct. 2018. Accessed on: Apr. 20, 2019. [Online]. Available at URL: https://www.hkma.gov.hk/eng/key-information/pressreleases/2018/20181031-4.shtml.
[30] Business Wire, "AlipayHK and GCash Launch Cross-Border Remittance Service Powered by Alipay's Blockchain Technology”, Jun. 2018. Accessed on: Aug. 8, 2018. [Online]. Available at URL:

https://www.businesswire.com/news/home/20180625005561/en/. [31] A. Antonovici, "Bank of China HK Uses Blockchain for $85 \%$ of Real Estate Valuations”, Cryptovest, Apr. 2018. Accessed on: Sep. 10, 2018. [Online]. Available at URL: https://cryptovest.com/news/bankof-china-hk-uses-blockchain-for-85-of-real-estate-valuations/.

[32] W. Zhao, "Hong Kong to Expedite Immigration for Blockchain Job Seekers”, coindesk, Aug. 2018. Accessed on: Sep. 12, 2018. [Online]. Available at URL: https://www.coindesk.com/hong-kong-to-expediteimmigration-for-blockchain-job-seekers.

[33] Y. Hagiwara, and Y. Nakamura, "Japan Unveils Guidelines for Allowing Initial Coin Offerings”, Bloomberg, Apr. 2018. Accessed on: Sep. 27, 2018. [Online]. Available at URL:

https://www.bloomberg.com/news/articles/2018-04-05/japan-plansfirst-step-toward-legalizing-initial-coin-offerings.

[34] Tama University, (2018), "Call for Rule-Making on ICO”, Apr. 2018. Accessed on: Sep. 7, 2018. [Online]. Available:

https://www.tama.ac.jp/crs/2018_ico_en.pdf.

[35] Nomura Research Institute, "Survey on Blockchain Technologies and Related Services FY2015 Report”, Mar. 2016. Accessed on: Aug. 28, 2018. [Online]. Available: http://www.meti.go.jp/english/press/2016/pdf/0531_01f.pdf. [36] Information Economy Division, Commerce and Information Policy Bureau, "Evaluation Forms for Blockchain-based System ver. 1.0”, Ministry of Economy, Trade and Industry, 2017.

[37] Information Economy Division, Commerce and Information Policy Bureau, "Survey on Technology and Institution related to Distributed System", Ministry of Economy, Trade and Industry, 2018.

[38] T. Wilson, "Expert Shortage Hampers Japanese Financials in Blockchain Race", Aug. 2016. Accessed on: Oct. 2, 2018. [Online]. Available at URL: https://www.reuters.com/article/us-japan-fintechblockchain-idUSKCN10S2GN.

[39] Ministry of Economy, Trade and Industry, "Japan Startup Selection" - The Participants of 2016 "HIYAKU Next Enterprise" Program”, 2017. Accessed on: Sep. 30, 2018. [Online]. Available: http://www.meti.go.jp/english/press/2017/pdf/0105_001a.pdf. [40] D. Cullinan, “World's First Bank-Backed Crypto Exchange Opens For Trading”, BitcoinNews.com, Jul. 2018. Accessed on: Sep. 27, 2018. [Online]. Available at URL: https://bitcoinnews.com/worlds-first-bankbacked-crypto-exchange-opens-for-trading/.

[41] Mizuho Financial Group, Inc., "Collaborating to Create Japan's First Blockchain Coworking Space”, May 2018. Accessed on: Sep. 30, 2018.

[Online]. Available: https://www.mizuho-

fg.com/release/pdf/20180518release_eng.pdf.

[42] Finolab, "About us - FINOLAB”, 2018. Available at URL: https:// finolab.tokyo/\#aboutus.

[43] A. Santo, I. Minowa, G. Hosaka, S. Hayakawa, M. Kondo, S. Ichiki, and Y. Kaneko, "Applicability of Distributed Ledger Technology to Capital Market Infrastructure (Vol. 15)", Japan Exchange Group, Aug. 2016.

[44] NTT DATA Corporation, "MUFG and NTT DATA Lay Foundation for Digital Trade Between Singapore and Japan Using Blockchain", Dec. 2017. Accessed on: Sep. 28, 2018. [Online]. Available 
at URL: https://www.nttdata.com/global/en/media/pressrelease/2017/december/mufg-and-ntt-data-lay-foundation-for-digitaltrade-between-singapore-and-japan-using-blockchain.

[45] NTT DATA Corporation and Skuchain, Inc., "NTT DATA will Develop a Business Collaboration Platform for Japanese Manufacturers in Cooperation with Skuchain in the U.S", Jan. 2018. Accessed on: Sep. 28, 2018. [Online]. Available at URL: http://www.skuchain.com/nttdata-will-develop-a-business-collaboration-platform-for-japanesemanufacturers-in-cooperation-with-skuchain-in-the-u-s/.

[46] Sumitomo Mitsui Financial Group, "Demonstration Test of Blockchain Technology in Cross-Border Trade Operations”, Dec. 2017. Accessed on: Aug. 28, 2018. [Online]. Available at URL: http://www.smfg.co.jp/news_e/e110076_01.html.

[47] I. Ueno, "Japanese Financial Institution and FinTech", Mizuho Financial Group, 2017.

[48] Mitsubishi UFJ Financial Group, "Fintech, Blockchain and Digital Currencies”, Mar. 2016. Accessed on: Sep. 30, 2018. [Online]. Available at URL:

https://www.mufg.jp/english/ourbrand/featuredarticle/2016_03.html. [49] Nikkei, "Japan Looks to Blockchains for More Secure E-

Government Systems”, Asian Review, Jun. 2017. Accessed on: Sep. 27, 2018. [Online]. Available at URL: https://asia.nikkei.com/Politics-

Economy/Policy-Politics/Japan-looks-to-blockchains-for-more-securee-government-system.

[50] Japanese Bankers Association, "Report of the Review Committee for the Possibility and the Challenges of Utilizing Blockchain

Technology", Japanese Bankers Association, 2017.

[51] Bank of Japan, "Message from Governor Kuroda on the Occasion of the Establishment of the FinTech Center", Apr. 2016. Accessed on: Sep. 29, 2018. [Online]. Available at URL:

https://www.boj.or.jp/en/paym/fintech/message.htm/.

[52] European Central Bank and Bank of Japan, "Payment Systems: Liquidity Saving Mechanisms in a Distributed Ledger Environment",

Sep. 2017. Accessed on: Sep. 29, 2018. [Online]. Available:

https://www.boj.or.jp/en/announcements/release_2017/data/rel17090 6a1.pdf.

[53] European Central Bank and Bank of Japan, "Securities Settlement Systems: Delivery-versus-Payment in a Distributed Ledger Environment”, Mar. 2018. Accessed on: Sep. 28, 2018. [Online].

Available:

https://www.boj.or.jp/en/announcements/release_2018/data/rel18032 7a1.pdf.

[54] S. Matsuo, "BSafe.network: Current Member Universities", Bsafe.network, May 2019. Accessed on: May. 10, 2019. [Online]. Available at URL: http://bsafe.network/member-university/.

[55] S. Takagi, H. Tanaka, M. Takemiya, and Y. Fujii, "Blockchain-Based Digital Currencies for Community Building”, GLOCOM, 2017.

[56] Keio Research Institute at SFC, "Announcement of BASE Alliance Establishment”, Jul. 2017. Accessed on: Sep. 18, 2018. [Online].

Available:

https://www.kri.sfc.keio.ac.jp/ja/press_file/20170724_base_en.pdf. [57] HAW International Inc., "Blockchain Technology Research Lab Established Within the Institute of Information Engineering Research at the Kyushu Institute of Technology”, Mar. 2018. Accessed on: Oct. 1, 2018. [Online]. Available: http://www.chaintope.com/en/wpcontent/uploads/sites/2/2018/03/0306_PRESS_BC_KIT_EN_2.pdf.
[58] Monetary Authority of Singapore, "Fintech Regulatory Sandbox Guidelines”, 2016. Accessed on: Sep. 30, 2018. [Online]. Available: https://www.mas.gov.sg/-/media/MAS/Smart-Financial-

Centre/Sandbox/FinTech-Regulatory-Sandbox-Guidelines19Feb2018.pdf?la=en\&hash=1F4AA49087F9689249FB8816A11AEAA 6CB3DE833.

[59] J. Lee, "MAS Slaps Warnings on 8 Cryptocurrency Exchanges; Bars ICO Issuer”, Business Times, May 2018. Accessed on: Sep. 8, 2018. [Online]. Available at URL: https://www.businesstimes.com.sg/bankingfinance/mas-slaps-warnings-on-8-cryptocurrency-exchanges-bars-icoissuer.

[60] Startup Genome, “Global Startup Ecosystem Report 2018”, San Francisco: Startup Genome LLC, 2018.

[61] Techinasia.com, "Tech in Asia - Meet the 15 top-funded blockchain companies in Singapore”, May 2018. Accessed on: Oct. 6, 2018. [Online]. Available at URL: https://www.techinasia.com/.

[62] ICO Watchlist, (2018), "ICO Statistics - By Country", 2018.

Accessed on: Sep. 12, 2018. [Online]. Available at URL:

https://icowatchlist.com/statistics/geo.

[63] W. A. Kaal, "Initial Coin Offerings: the Top 25 Jurisdictions and

Their Comparative Regulatory Responses", CodeX Stanford Journal of

Blockchain Law \& Policy, U of St. Thomas (Minnesota) Legal Studies

Research Paper No. 18-07, 2018. Available:

dx.doi.org/10.2139/ssm.3117224.

[64] U-W. Lee, "Record S\$19b Set Aside for R\&D Until 2020”, Business Times, Jan. 2016. Accessed on: Sep. 1, 2018. [Online]. Available at URL: https://www.businesstimes.com.sg/government-economy/singaporesfuture-economy/record-s19b-set-aside-for-rd-until-2020.

[65] F. Ungku, "IBM to open first blockchain innovation center in Singapore”, Reuters, Apr. 2016. Accessed on: Sep. 28, 2018. [Online]. Available at URL: https://www.reuters.com/article/us-ibm-fintechsingapore/ibm-to-open-first-blockchain-innovation-center-in-singaporeidUSKCNOZS03Y.

[66] National University of Singapore, "NUS Computing forms academic blockchain think tank", Sep. 2018. Accessed on: Sep. 25, 2018. [Online]. Available at URL: https://news.nus.edu.sg/press-releases/CRYSTALcentre.

[67] Y. Yoon, “Korean Gov't Unveils Blockchain Technology Development Strategy”, Business Korea, Jun. 2018. Accessed on: Sep 8, 2018. [Online]. Available at URL:

http://www.businesskorea.co.kr/news/articleView.html?idxno=23184. [68] W. Zhao, "PBoC filings reveal big picture for planned digital currency”, coindesk, Jul. 2018. Accessed on: Sep. 29, 2018. [Online]. Available at URL: https://www.coindesk.com/pboc-filings-reveal-bigpicture-for-planned-digital-currency/.

[69] R. R. O'Leary, "South Korean Regulator Issues ICO Ban”, coindesk, Sep. 2017. Accessed on: Sep. 1, 2018. [Online]. Available at URL: https://www.coindesk.com/south-korean-regulator-issues-ico-ban/. [70] FSC, "FSC Reshuffles Organizational Structure”, Jul. 2018. Accessed on: Sep. 7, 2018. [Online]. Available at URL:

https://www.fsc.go.kr/eng/new_press/releases.jsp?menu=01\&bbsid=B BS0048.

[71] K. Helms, "Only 12 out of 23 Korean Crypto Exchanges Pass Probe - Inspector Under Fire”, Bitcoin.com, Jul. 2018. Accessed on: Sep. 12, 2018. [Online]. Available at URL: https://news.bitcoin.com/only-12out-of-23-korean-crypto-exchanges-pass-probe-inspector-under-fire/. 
[72] Muzika, "Muzika Project Teaser", 2018. Accessed on: Sep. 20, 2018. [Online]. Available: https://www.muzika.network/assets/mzk-teaseren.pdf.

[73] J. Kim, “South Korean Gov't to Invest $\$ 200$ Mln in Blockchain Initiatives”, Cryptoslate, Jun. 2018. Accessed on: Sep. 6, 2018. [Online]. Available at URL: https://cryptoslate.com/south-korean-govt-to-invest200-mln-in-blockchain-initiatives.

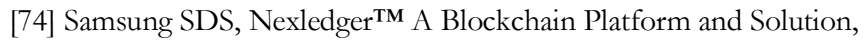
White paper, 2017.

[75] M. H. Cho, "LG CNS Launches Monachain Blockchain Platform", ZDNet, May 2018. Accessed on: Aug. 20, 2018. [Online]. Available at

i Consolidated information from World Intellectual Property Organisation and IPR Daily statistics on blockchain patents between 2008 to 2018 .

ii Source: CBInsights (https://www.cbinsights.com/research/unicorn-startupmarket-map/)

iii Special Administrative Region (SAR)

iv $R \& D$ spending as per cent of GDP of APAC countries, World Development Indicators by the World Bank.

v http://www3.weforum.org/docs/GITR2016/WEF_GITR_Full_Report.pdf

http://www.eiu.com/Handlers/WhitepaperHandler.ashx?fi=Technological_readi ness_report.pdf\&mode $=$ wp\&campaignid $=$ TechReadiness

vii Data obtained from ICOWatchList.com. https://icowatchlist.com/statistics/geo
URL: https://www.zdnet.com/article/lg-cns-launches-monachainblockchain-platform/.

viii Search volume of a 1-year period from 7 Oct, 2017 to 7 Oct, 2018. https://trends.google.com/trends/explore? $\mathrm{q}=\% 2 \mathrm{Fm} \% 2 \mathrm{~F} 0138 \mathrm{n} 0 \mathrm{j} 1$ ix Results are based on the Venture Capital \& Private Equity Country Attractiveness Index by IESE Business School, University of Navarra. https://blog.iese.edu/vcpeindex/ranking/

x A full list of national currencies exchanged for the 24 hours of total bitcoin volume can be found at the Coinhills website:

https://www.coinhills.com/market/currency/

xi https://news.8btc.com/1-6-billion-government-backed-blockchain-fundlaunched-in-hangzhou

xii https:/ / www.coindesk.com/another-1-billion-blockchain-fund-to-launch-withgovernment-backing 